\title{
Smokeless Tobacco Use
}

National Cancer Institute

\section{Source}

National Cancer Institute. Smokeless Tobacco Use. NCI Thesaurus. Code C137998.

Use of smokeless tobacco in any form, e.g., chewing or sniffing. 